\title{
Fifty Years of Research and One Conclusion: Opium Causes Cancer
}

\author{
Mahdi Sheikh, MD ${ }^{1,2}$; Farin Kamangar, MD, PhD; Reza Malekzadeh, MD ${ }^{2,4^{*}}$ \\ ${ }^{1}$ Genetic Epidemiology Group, Section of Genetics, International Agency for Research on Cancer, World Health Organization, Lyon, France \\ ${ }^{2}$ Digestive Oncology Research Center, Digestive Diseases Research Institute, Tehran University of Medical Sciences, Tehran, Iran \\ ${ }^{3}$ Department of Biology, School of Computer, Mathematical, and Natural Sciences, Morgan State University, Baltimore, MD, USA \\ ${ }^{4}$ Digestive Disease Research Center, Digestive Diseases Research Institute, Tehran University of Medical Sciences, Tehran, Iran
}

\begin{abstract}
In September 2020, the International Agency for Research on Cancer (IARC) announced that opium consumption causes cancer in humans - a conclusion drawn after reviewing data from five decades of research. Given the widespread use of opium and its derivatives by millions of people across the world, the classification of opium consumption as a "Group 1" carcinogen has important public health ramifications. In this mini-review, we offer a short history of opium use in humans and briefly review the body of research that led to the classification of opium consumption as carcinogenic. We also discuss possible mechanisms of opium's carcinogenicity and potential avenues for future research.

Keywords: Carcinogen, Case-control studies, Cohort studies, Neoplasm, Opiate, Opioids

Cite this article as: Sheikh M, Kamangar F, Malekzadeh R. Fifty years of research and one conclusion: opium causes cancer. Arch Iran Med. 2020;23(11):757-760. doi: 10.34172/aim.2020.95.
\end{abstract}

Received: October 8, 2020, Accepted: October 14, 2020, ePublished: October 17, 2020

\section{Introduction}

In September 2020, a Working Group of international experts convened by the International Agency for Research on Cancer (IARC) concluded that opium consumption is carcinogenic to humans. A summary of the findings is published in the Lancet Oncology, ${ }^{1}$ and the full results will be published in the volume 126 of IARC Monographs. With this conclusion, opium consumption joins the rank of tobacco smoking, alcohol consumption, aflatoxin exposure, and other agents classified as Group 1 Carcinogens.

The Working Group's conclusion was based on five decades of research. While it may seem quite long, 50 years is only a short span compared to the long history of opium use in human populations. Over thousands of years, it has been used for recreational and medicinal purposes. It has brought people together in ceremonies, and against each other in wars. It has made some rich and others poor. It has been used to pacify children and to kill powerful people. Here, we offer a short history of opium use and will succinctly review the body of research that convinced the IARC Working Group of opium's carcinogenicity. We also discuss possible mechanisms of carcinogenicity and potential lines for future research.

\section{Opium Use through the History}

Opium is the air-dried latex obtained from the unripe seedpod of the poppy plant (Papaver somniferum), and has addictive and narcotic features. It has been used in traditional medicine for various purposes - to alleviate pain, prevent cough, and treat diarrhea, among others via oral, topical, rectal, and intranasal routes. The analgesic properties of opium were noted by Hippocrates around $460 \mathrm{BCE}$, and Galen around $200 \mathrm{CE}^{2}$ Opium's other medicinal and adverse effects were described by Avicenna in "The Canon of Medicine" around 1025 CE. ${ }^{3}$ Opium poppy was cultivated in Mesopotamia (3400 BCE), Egypt (1500 BCE), and Greece (1100 BCE). ${ }^{4,5}$ It was spread to Persia and India following the conquests of Alexander the Great (330 BCE), and later to China by Arab traders. ${ }^{6}$ During the 11 th to 17 th centuries, opium use spread to the rest of the world including Europe and the New World, and a large number of people across the world became addicted to opium use. ${ }^{7}$ In the 19th century, following the banning of opium trade by the Qing dynasty of China, two major opium wars were carried out by the British and French empires against the Qing dynasty. ${ }^{8}$ These wars ended with more than twenty thousand casualties by defeat of the Chinese forces and compelling the Chinese government to grant favorable tariffs, trade concessions, and territory to the Western empires. ${ }^{8}$ Having observed destruction, abuse, and dependency related to opium use, the governments of 56 countries took action in 1925 by signing the International Opium Convention, 
agreeing to prohibit the cultivation or manufacture, import, sales, distribution, export, and use of narcotic drugs, except for medical and scientific purposes. ${ }^{9}$ Despite this agreement, the use of opium and its derivatives (opiates) is still widespread, as in 2018 an estimated 30 million people had illicitly used opiates worldwide. ${ }^{10}$ The widespread use of opium is concerning not only for its short-term addictive effects or long-term productivity loss, but also for its potential to cause cardiovascular diseases ${ }^{11}$ or cancers. ${ }^{12}$

\section{Fifty years of Investigations on Opium Use and Cancer Risk}

Some of the first clues on the possible link between opium use and cancer came from clinical observations in the late 1960s and the early 1970s. Lyons and Yazdi published a paper in 1969 implicating opium smoking as a potential cause of cancer of the tongue. ${ }^{13}$ Dowlatshahi and colleagues conducted clinical studies of esophageal cancer patients in northeast of Iran, where esophageal cancer was very common, while the known risk factors such as tobacco use and alcohol consumption were uncommon. ${ }^{14}$ They found a high prevalence of opium use among esophageal cancer patients and observed burnt opium residues in their esophagus during their endoscopic examinations, leading to the hypothesis that it may be opium that plays the carcinogenic role of tobacco smoking in northeastern Iran. ${ }^{14}$ Shortly after that, an ecologic study in northern parts of Iran found a substantially higher prevalence of urinary opium metabolites among residents of the high-risk areas, compared to low-risk areas, related to esophageal cancer. ${ }^{15}$ In the late 1970 s and early 1980s, several case-control and cross-sectional studies were published from Iran, Hong Kong, and Singapore showing associations between opium use and higher risk of cancers of the larynx, ${ }^{16}$ bladder, ${ }^{17,18}$ lung, ${ }^{19}$ and esophagus. ${ }^{20}$ Simultaneously, experimental studies showed the presence of several mutagens in opium dross and opium pyrolysates and documented the genotoxic effects related to these ingested types of opium. ${ }^{21-23}$ Following the sociopolitical changes of 1980s in Iran, scientific studies on opium and cancer came to a halt for over 20 years.

Studies of opium use and cancer resumed in the early 2000s, almost exclusively in Iran, where opium consumption was common and an infrastructure was being developed to conduct high-quality epidemiologic studies. An early example was the 2003 study of Mousavi and colleagues that showed a strong positive association between opium use and laryngeal cancer. ${ }^{24}$ In 2002, an important case-control study named GEMINI (Gastroesophageal and Esophageal Malignancies in Northern Iran) was planned to investigate the risk factors of esophageal and gastric cancers in the Golestan Province, northern Iran. ${ }^{25}$ This was a follow-up to the unfinished studies conducted before the Iranian revolution. Detailed questionnaires were developed to assess opium use, as opium was one of the culprits for the high rates of esophageal cancer in the area. ${ }^{25}$ A very influential study, the Golestan Cohort Study (GCS), was launched by the same group of investigators, and hence, GCS essentially used the same questionnaires as GEMINI. ${ }^{26}$ However, for several reasons, GCS was a pivotal study and took studies of opium use and cancer to a higher level. First, GCS validated the opium use questionnaire against urinary opium metabolites, and showed very good validity and reliability for reporting opium use. ${ }^{27}$ As such, that same questionnaire was used in at least 12 subsequent epidemiologic studies to assess opium use and cancer risk. ${ }^{28-39}$ Second, GCS was the first study to prospectively follow a large number of opium users for more than a decade with a negligible loss to followup, allowing robust investigation of the risk of different cancer outcomes among these individuals. ${ }^{12}$ Altogether, since 2003, at least 25 independent case-control, ${ }^{24,28-38,40-52}$ and 2 cohort studies ${ }^{12,39}$ have been conducted on this subject and nearly all have shown increased risk of cancers of different sites among opium users. Reviewing the results of all studies conducted over the past 50 years, the IARC Working Group found "sufficient evidence" for the carcinogenicity of opium consumption in relation to cancers of the larynx, lung, and bladder, and "limited evidence" for the carcinogenicity of opium for cancers of the esophagus, stomach, pharynx, and pancreas. ${ }^{1}$

\section{Proposed Mechanisms for the Carcinogenicity of Opium Use}

The carcinogenic mechanisms of opium consumption are not clear. Opium is a complex mixture, with alkaloid (e.g., morphine and thebaine) and non-alkaloid (e.g., water and sugar) components, and it is often contaminated and/or adulterated with lead, chromium, and other chemicals. Opium may be smoked or ingested, and comes in various forms (e.g., raw [teriak], minimally refined [shireh], and dross [sukhteh]). ${ }^{53,54}$ This complexity makes assessment of the mechanisms difficult. However, several mechanisms have been suggested for this causal relationship: (1) Opium pyrolysates have shown genotoxic/mutagenic effects. $^{21-23}$ The IARC Working Group found "strong evidence" of genotoxicity by opium ${ }^{1}$; (2) Opium use may promote tumorigenesis by inducing angiogenesis, ${ }^{55}$ immunosuppression, ${ }^{56}$ and facilitating cancer cell proliferation and migration ${ }^{55}$; 3) Opium may change the tone of the lower esophageal sphincter and the bladder sphincter, allowing prolonged exposure of these organs to cancer. ${ }^{54}$ Extended exposure may also happen by opium's effect on modifying the pharmacokinetics and bioavailability of various carcinogens ${ }^{57}$; and (4) The impurities and adulterations of opium by compounds like lead and arsenic, ${ }^{58,59}$ which are unfortunately inextricably linked to use, may also play a role. 


\section{Future Research Directions}

The classification of opium consumption as a "Group 1" carcinogen by the IARC is clearly an important milestone. Yet, there is much more research to be done. The effect of opium use on several cancers such as cancers of the esophagus, stomach, pharynx, and pancreas should be investigated further in well-conducted studies. Research on the carcinogenic mechanisms of opium use has barely scratched the surface, and there is a huge potential for research in this area. The results reached by the IARC apply only to minimally processed opium, which is a complex mixture; it is unclear whether pure forms of naturally occurring opiates (e.g., morphine) or semi-synthetic or synthetic opioids (e.g., fentanyl and tramadol) also cause cancer. Given the widespread use of these opioids all across the world, conducting careful studies are of utmost importance. We invite all scientists with relevant research interests to contribute to this field. The 2020 IARC Working Group meeting was the culmination of 50 years of research, yet the beginning of another era of research on opium use and cancer. .

\section{Authors' Contribution}

MSh wrote the first draft of manuscript, and collected the data. FK and RM collaborated in collection of data, and edited and critically reviewed the manuscript. All authors read and approved the final manuscript.

\section{Conflict of Interest Disclosures}

None.

\section{Ethical Statement}

Not applicable.

\section{Disclaimer}

Where authors are identified as personnel of the International Agency for Research on Cancer / World Health Organization, the authors alone are responsible for the views expressed in this article and they do not necessarily represent the decisions, policy or views of the International Agency for Research on Cancer / World Health Organization.

\section{References}

1. Warnakulasuriya S, Cronin-Fenton D, Jinot J, Kamangar F, Malekzadeh R, Dar NA, et al. Carcinogenicity of opium consumption. Lancet Oncol. doi:10.1016/S14702045(20)30611-2.

2. Stefano GB, Pilonis N, Ptacek R, Kream RM. Reciprocal Evolution of Opiate Science from Medical and Cultural Perspectives. Med Sci Monit. 2017;23:2890-6. doi:10.12659/ MSM.905167.

3. Mahdizadeh S, Khaleghi Ghadiri M, Gorji A. Avicenna's Canon of Medicine: a review of analgesics and anti-inflammatory substances. Avicenna J Phytomed. 2015;5(3):182-202.

4. Booth M. Opium: A History. St. Martin's Press; 1998

5. Tsoucalas G, Markatos K, Korres D, Karamanou M. Diagoras of Cyprus (3rd century BC) - an eminent oculist and opposer to the use of opium. Arch Balk Med Union. 2018;53:179-83. doi:10.31688/ABMU.2018.53.3.22.

6. Tétényi P. Opium Poppy (Papaver somniferum): Botany and Horticulture. In: Horticultural Reviews. John Wiley \& Sons, Ltd; 2010:373-408. doi:10.1002/9780470650622.ch7.

7. Aragón-Poce F, Martínez-Fernández E, Márquez-Espinós C, Pérez A, Mora R, Torres LM. History of opium. International Congress Series. 2002;1242:19-21. doi:10.1016/S0531-
5131(02)00600-3.

8. Kamienski L. Shooting Up: A Short History of Drugs and War. Oxford University Press; 2016.

9. United Nations Treaty Collection. International Opium Convention. 1925. Available from: https://treaties.un.org/ pages/ViewDetails.aspx?src $=$ TREATY \&mtdsg_no=VI-6a\&chapter $=6$ \&clang=_en .

10. United Nations Office on Drugs and Crime. World Drug Report 2020. 2020. Available from: https://wdr.unodc.org/wdr2020/ index.html.

11. Nalini M, Shakeri R, Poustchi H, Pourshams A, Etemadi A, Islami F, et al. Long-term opiate use and risk of cardiovascular mortality: results from the Golestan Cohort Study. Eur J Prev Cardiol. 2020. doi:10.1093/eurjpc/zwaa006.

12. Sheikh M, Shakeri R, Poustchi H, Pourshams A, Etemadi A, Islami $F$, et al. Opium use and subsequent incidence of cancer: results from the Golestan Cohort Study. Lancet Glob Health. 2020;8(5):e649-e660. doi:10.1016/S2214-109X(20)30059-0.

13. Lyons DC, Yazdi I. Lyons DC, Yazdi I. The carcinogenic potentials of'opium smoker's tongue'. J Oral Med. 1969;24(3):67-72.

14. Dowlatshahi K, Miller RJ. Role of opium in esophageal cancer: a hypothesis. Cancer Res. 1985;45(4):1906-7.

15. Joint Iran-International Agency for Research on Cancer Study Group. Esophageal Cancer Studies in the Caspian Littoral of Iran: Results of Population Studies-A Prodrome. J Natl Cancer Inst. 1977;59(4):1127-38. doi:10.1093/jnci/59.4.1127.

16. Khoo R. Radiotherapy of carcinoma of the Larynx. Ann Acad Med Singap. 1981;10(3):307-10.

17. Sadeghi A, Behmard S, Vesselinovitch SD. Opium: a potential urinary bladder carcinogen in man. Cancer. 1979;43(6):231521. doi: 10.1002/1097-0142(197906)43:6<2315::aidcncr2820430622>3.0.co;2-j.

18. Behmard S, Sadeghi A, Mohareri MR, Kadivar R. Positive association of opium addiction and cancer of the bladder. Results of urine cytology in 3,500 opium addicts. Acta Cytol. 1981;25(2):142-6.

19. MacLennan $\mathrm{R}$, Da Costa J, Day NE, Law $\mathrm{CH}, \mathrm{Ng} \mathrm{YK}$, Shanmugaratnam K. Risk factors for lung cancer in Singapore Chinese, a population with high female incidence rates. Int J Cancer. 1977;20(6):854-60. doi:10.1002/ijc.2910200606.

20. Ghadirian P, Stein GF, Gorodetzky C, Roberfroid MB, Mahon GA, Bartsch $\mathrm{H}$, et al. Oesophageal cancer studies in the Caspian littoral of Iran: some residual results, including opium use as a risk factor. Int J Cancer. 1985;35(5):593-7.

21. Hewer T, Rose E, Ghadirian P, Castegnaro M, Malaveille C, Bartsch $\mathrm{H}$, et al. Ingested mutagens from opium and tobacco pyrolysis products and cancer of the oesophagus. Lancet. 1978;2(8088):494-6. doi:10.1016/s0140-6736(78)92218-3.

22. Malaveille C, Friesen M, Camus AM, Garren L, Hautefeuille A, Béréziat JC, et al. Mutagens produced by the pyrolysis of opium and its alkaloids as possible risk factors in cancer of the bladder and oesophagus. Carcinogenesis. 1982;3(5):577-85.

23. Friesen M, O'neill IK, Malaveille C, Garren L, Hautefeuille A, Cabral JR, et al. Characterization and identification of 6 mutagens in opium pyrolysates implicated in oesophagel cancer in Iran. Mutat Res. 1985;150(1):177-91. doi:10.1016/00275107(85)90114-9.

24. Mousavi MRA, Damghani MA, Haghdoust AA, Khamesipour A. Opium and risk of laryngeal cancer. Laryngoscope. 2003;113(11):1939-43. doi: 10.1097/00005537-20031100000016.

25. Sepanlou SG, Etemadi A, Kamangar F, Pourshams A, Poustchi H, Islami $F$, et al. The gastro-esophageal malignancies in Northern Iran research project: impact on the health research and health care systems in Iran. Arch Iran Med. 2013;16(1):46-53. doi:013161/AIM.0014.

26. Pourshams A, Khademi H, Malekshah AF, Islami F, Nouraei M, Sadjadi AR, et al. Cohort profile: the Golestan Cohort Study-a prospective study of oesophageal cancer in northern Iran. Int J Epidemiol. 2010;39(1):52-9. doi:10.1093/ije/dyp161.

27. Abnet CC, Saadatian-Elahi M, Pourshams A, Boffetta P, 
Feizzadeh A, Brennan P, et al. Reliability and validity of opiate use self-report in a population at high risk for esophageal cancer in Golestan, Iran. Cancer Epidemiol Biomarkers Prev. 2004;13(6):1068-70.

28. Shakeri R, Kamangar F, Nasrollahzadeh D, Nouraie M, Khademi $\mathrm{H}$, Etemadi $\mathrm{A}$, et al. Is opium a real risk factor for esophageal cancer or just a methodological artifact? Hospital and neighborhood controls in case-control studies. PLoS One. 2012;7(3):e32711. doi:10.1371/journal.pone.0032711.

29. Nasrollahzadeh D, Kamangar F, Aghcheli K, Sotoudeh M, Islami F, Abnet CC, et al. Opium, tobacco, and alcohol use in relation to oesophageal squamous cell carcinoma in a high-risk area of Iran. Br J Cancer. 2008;98(11):1857-63. doi:10.1038/ sj.bjc.6604369.

30. Akbari M, Naghibzadeh-Tahami A, Khanjani N, Baneshi MR, Kamali E, Hesampour M, et al. Opium as a Risk Factor for Bladder Cancer: A Population-based Case-control Study in Iran. Arch Iran Med. 2015;18(9):567-71.

31. Masjedi MR, Naghan PA, Taslimi S, Yousefifard M, Ebrahimi SM, Khosravi A, et al. Opium could be considered an independent risk factor for lung cancer: a case-control study. Respiration. 2013;85(2):112-8. doi:10.1159/000338559.

32. Alizadeh $H$, Naghibzadeh-Tahami A, Khanjani N, YazdiFeyzabadi V, Eslami H, Borhaninejad V, et al. Opium Use and Head and Neck Cancers: A Matched Case-Control Study in Iran. Asian Pac J Cancer Prev. 2020;21(3):783-790. doi:10.31557/ APJCP.2020.21.3.783.

33. Naghibzadeh-Tahami A, Marzban M, Yazdi-Feyzabadi V, Dabiri S, Mohseni S, Rayeni RA, et al. Is opium use associated with an increased risk of lung cancer? A case-control study. BMC Cancer. 2020;20:870. doi:10.1186/s12885-020-07296-0.

34. Shakeri R, Malekzadeh R, Etemadi A, Nasrollahzadeh D, Aghcheli K, Sotoudeh M, et al. Opium: an emerging risk factor for gastric adenocarcinoma. Int J Cancer. 2013;133(2):455-61. doi:10.1002/ijc.28018.

35. Naghibzadeh Tahami A, Khanjani N, Yazdi Feyzabadi V, Varzandeh M, Haghdoost A-A. Opium as a risk factor for upper gastrointestinal cancers: a population-based case-control study in Iran. Arch Iran Med. 2014;17(1):2-6.

36. Naghibzadeh-Tahami A, Feyzabadi VY, Khanjani N, AshrafiAsgarabad A, Alizaeh H, Borhaninejad VR, et al. Can opium use contribute to a higher risk of colorectal cancers? A matched casecontrol study in Iran. Iran J Public Health. 2016;45(10):13221331.

37. Shakeri R, Kamangar F, Mohamadnejad M, Tabrizi R, Zamani F, Mohamadkhani A, et al. Opium use, cigarette smoking, and alcohol consumption in relation to pancreatic cancer. Medicine. 2016;95(28):e3922. doi:10.1097/MD.0000000000003922.

38. Lankarani KB, Khosravizadegan Z, Naghibzadeh-Tahami A, Akbari M, Khodadost M, Honarvar B, et al. Opium Use and Risk of Lower Gastrointestinal Cancers: Population-Based CaseControl Study in South of Iran. Int J Cancer Manag. 2017;10(6). doi:10.5812/ijcm.8227.

39. Sadjadi A, Derakhshan $M H$, Yazdanbod A, Boreiri $M$, Parsaeian M, Babaei $M$, et al. Neglected role of hookah and opium in gastric carcinogenesis: a cohort study on risk factors and attributable fractions. Int J Cancer. 2014;134(1):181-8. doi:10.1002/ijc.28344.

40. Bakhshaee M, Raziee HR, Afshari R, Amali A, Roopoosh M, Lotfizadeh A. Opium Addiction and Risk of Laryngeal and Esophageal Carcinoma. Iran J Otorhinolaryngol. 2017;29(1):1922. doi:10.22038/ijorl.2016.8055.

41. Pournaghi SJ, Hojjat SK, Barazandeh Noveyri F, Tavakkoli Ghouchani H, Ahmadi A, Hamedi A, et al. Tobacco consumption, opium use, alcohol drinking and the risk of esophageal cancer in North Khorasan, Iran. J Subst Use. 2019;24(1):105-9. doi:10. 1080/14659891.2018.1523962.

42. Aliasgari MA, Kaviani A, Gachkar L, Hosseini-Nassab SR. Is bladder cancer more common among opium addicts? Urol J. 2004;1(4):253-5.

43. Hosseini SY, Safarinejad MR, Amini E, Hooshyar H. Opium consumption and risk of bladder cancer: A case-control analysis. Urol Oncol. 2010;28(6):610-6. doi:10.1016/j. urolonc.2008.10.016.

44. Shakhssalim N, Hosseini SY, Basiri A, Eshrati B, Mazaheri M, Soleimanirahbar A. Prominent bladder cancer risk factors in Iran. Asian Pac J Cancer Prev. 2010;11(3):601-6.

45. Aliramaji A, Kaseean A, Yousefnia Pasha YR, et al. Age distribution types of bladder cancers and their relationship with opium consumption and smoking. Caspian J Intern Med. 2015;6(2):82-6.

46. Ghadimi T, Gheitasi B, Nili S, Karimi M, Ghaderi E. Occupation, smoking, opium, and bladder cancer: A casecontrol study. South Asian Journal of Cancer. 2015;4(3):111. doi:10.4103/2278-330x.173174.

47. Lotfi $\mathrm{MH}$, Farzaneh $\mathrm{F}$, Mehrparvar $\mathrm{AH}$, Fallahzadeh $\mathrm{MH}$, Sadeghian MR. The Effect of Smoking and Opium on Bladder Cancer in Yazd Province: A Case - Control Study. J Community Health Res. 2016;5(2):98-109.

48. Nezameddin B, Rogha M, Shahabeddini M. The Relationship between the Opium Drug and the Risk of Laryngeal Squamous Cell Cancer. Ambient Science. 2018;5. doi:10.21276/ ambi.2018.05.sp1.ta01.

49. Mohebbi E, Hadji M, Rashidian H, Rezaianzadeh A, Marzban M, Haghdoost AA, et al. Opium use and the risk of head and neck squamous cell carcinoma. International Journal of Cancer. doi:10.1002/ijc.33289.

50. Razmpa E, Saedi B, Motiee-langroudi M, Garajei A, Hoseinpor S, Motamedi MHK. Opium usage as an etiologic factor of oral cavity cancer. J Craniofac Surg. 2014;25(5):e505-507. doi:10.1097/SCS.0000000000001089.

51. Tahergorabi Z, Moodi M, Zardast M, Ghayravani Z, Tavakoli T. Metabolic Syndrome and the Risk of Gastrointestinal Cancer: a Case-Control Study. Asian Pac J Cancer Prev. 2018;19(8):220510. doi:10.22034/APJCP.2018.19.8.2205

52. Vazirinejad R, Najafipour R, Rezaeian M, Ghazizadeh A, Doost Mohammadi F. Opium and Risk of Gastrointestinal Cancer: A Case-Control Study. Turk J Med Sci. 2020. doi:10.3906/sag1907-100.

53. Kalant H. Opium revisited: a brief review of its nature, composition, non-medical use and relative risks. Addiction. 1997;92(3):267-77.

54. Kamangar F, Shakeri R, Malekzadeh R, Islami F. Opium use: an emerging risk factor for cancer?. Lancet Oncol. 2014;15(2):e6977. doi:10.1016/S1470-2045(13)70550-3.

55. Grandhi RK, Lee S, Abd-Elsayed A. Does Opioid Use Cause Angiogenesis and Metastasis? Pain Med. 2017;18(1):140-51. doi:10.1093/pm/pnw132.

56. Vallejo R, de Leon-Casasola O, Benyamin R. Opioid therapy and immunosuppression: a review. Am J Ther. 2004;11(5):35465. doi: 10.1097/01.mjt.0000132250.95650.85.

57. Ribeiro Pinto LF, Swann PF. Opium and oesophageal cancer: effect of morphine and opium on the metabolism of $\mathrm{N}$-nitrosodimethylamine and $\mathrm{N}$-nitrosodiethylamine in the rat. Carcinogenesis. 1997;18(2):365-9. doi:10.1093/ carcin/18.2.365.

58. Aghababaei R, Javadi I, Nili-Ahmadabadi A, Parsafar S Ahmadimoghaddam D. Occurrence of bacterial and toxic metals contamination in illegal opioid-like drugs in Iran: a significant health challenge in drug abusers. Daru. 2018;26(1):77-83. doi:10.1007/s40199-018-0205-5.

59. Wijesekera ARL, Henry KD, Ranasinghe P. The detection and estimation of (A) arsenic in opium, and (B) strychnine in opium and heroin, as a means of identification of their respective sources. Forensic Sci Int. 1988;36(3):193-209. doi:10.1016/0379-0738(88)90143-0. 